\title{
Registration in the Land Book of a River Section
}

\author{
Mircea Emil NAP1,2, Petre Iuliu DRAGOMIR², Tudor SĂLĂGEAN ${ }^{*}$, Ioana Delia POP1, Florica \\ MATEI ${ }^{1}$, Iulia COROIAN ${ }^{1}$, Jutka DEAK ${ }^{1}$, Silvia CHIOREAN ${ }^{1}$, Elemer-Emanuel ȘUBA ${ }^{1}$, Ioan \\ LUPUT $^{1}$
}

\author{
${ }^{1}$ Department of Land Measurements and Exact Sciences, Faculty of Horticulture, University of Agricultural Sciences \\ and Veterinary Medicine Cluj-Napoca, 3-5 Mănăștur St., 400372, Cluj-Napoca, Romania \\ 2 Department of Topography and Cadastre, Faculty of Geodesy, Technical University of Civil Engineering Bucharest, \\ 122-124 Lacul Tei Blvd., 2nd District, 020396, Bucharest, Romania \\ * Corresponding author: Tudor SĂLĂGEAN e-mail: tudor.salagean@usamvcluj.ro
}

RESEARCH ARTICLE

\begin{abstract}
The minor riverbed of the Someș River is identified in the built-up area and the outside of the built-up area of Fărcașa ATU and the Ardusat ATU outside the built-up area, from the Ardusat DJ 193 road bridge, between hm 2725-2855 and between hm 2815-2867, according to GD (Government Decision) 1705/2006. For the first registration work of the Someș minor riverbed, the measurements, their processing and the afferent documentation were made in accordance with the Order of the general director of the National Agency for Cadastre and Real Estate Advertising no. 700/2014, updated in 2020. The purpose of the project refers to the topo-cadastral methods performed for the elaboration of the documentation of first registration in the Land Book of the minor riverbed belonging to the Someș river located within the radius of ATU Ardusat and ATU Fărcașa from Maramureș county. For the acquisition of the necessary data, both field works and office operations for data processing were taken into account, the studied area being 222.7 hectares. Measurements were performed using GNSS technology using the real-time kinematic RTK method. The UAV aerial photogrammetric method was used to obtain a high degree of detail. The drone used was equipped with an RTK module that receives real-time corrections, thus maintaining a high accuracy.
\end{abstract}

Keywords: GPS; Land Book; UAV.

Received: 30 October 2020

Accepted: 20 April 2021

Published: 14 May 2021

DOI:

15835/buasvmen-hort:2020.0065

\footnotetext{
(C) published in this journal are licensed under the Creative Commons Attribution-NonCommercialNoDerivatives 4.0 International License
}

\section{INTRODUCTION}

The studied area is in Ardusat ATU and Fărcașa ATU, Maramureș County. The aim is to obtain the necessary data for the registration of the minor riverbed of the Somes River, so that measurements were made using GNSS technology and the UAV aerial photogrammetric method. In this way, the digital orthophotoplan was obtained, on which the minor riverbed was vectorized.

The property studied in this paper is part of the public domain of the state, according to GD 1705 of November 29, 2006, in the Someș Tisa Water Basin Administration according to GD 1176, being located on the surface of two ATUs, having an area of 222.7 hectares. In order to establish the limits, the comparison with the buildings previously registered in the database, the current course of the river and its banks was taken into account. It was necessary to georeference the old maps at a scale of 1 : 2880 to identify the topographic numbers of the existing buildings, followed by an onsite consultation with the owners. As a first step in this work was to identify the geodesic-topographic base in the area. In order to obtain the most accurate results, it was necessary to check and develop the support network. The considered surface is 
included in the plan sheetsL-34-23-B-a L-34-23-B-b, L-34-23-B-c and L-34-23-B-d. A geodetic network consists of several known coordinate points, in a given reference system, located along an area. The geodetic network is based on 2 networks, namely the leveling and gravimetric network (RNG) for altimetric positioning and the triangulationtrilateration network (RTT) for plan positioning. (Peyret et al., 2000; Treitz, 2004; Pirti et al., 2013)

The planimetric network consists of a series of chains of triangles distributed throughout the country and consists of 5 categories of points. Orders I-III are called higher order triangulation networks and those of order IV and $\mathrm{V}$, lower order.

The geodetic support network that was used for the execution of the present works consists of the following points: Bușag, La-Brazi, Colțirea, Pribilești-Nord, Sîrbi and 43. This creates a chain of triangles that frames the point to be thickened.

\section{MATERIALS AND METHODS}

The following instruments were used in carrying out this work: the Leica TCR805 Power total station, the South S82-V GNSS system and the DJI Phantom 4 RTK drone.

The Leica TCR805 Power Total Station is a high-quality, easy-to-use total electronic station and is manufactured by the Swiss company Leica Geosystem, a manufacturer of measuring equipment.

The South S82-V GNSS system uses state-of-the-art GNSS technologies and contains the Pacific Crest board that makes it possible to receive signals: GPS L1, L2, L2C and LC, GLONASS L1, L2 SBAS and Galileo and Compass. The receiver contains a GNSS antenna, GNSS mode and bluetooth.

The DJI Phantom 4 RTK UAV system has an integrated RTK module that receives signals from GNSS systems: Glonass, Galileo, GPS, and BeiDou. This makes it possible to position in real time with high accuracy, requiring a small number of ground control points. If the obstacle sensor is activated and there are good visibility conditions, the drone can reach a speed of $50 \mathrm{~km} / \mathrm{h}$.

Several measurement methods were used during the measurements:

The measurement of the horizontal angles was performed by the iteration method. This involves measuring angles in several iterations, series, at different origins.

The vertical angles are recorded directly with the help of the Total Station. The value of the slope angle $\alpha$ or the value of the zenith angle $\mathrm{z}$ can be recorded.

The triangulation method was used to verify the support network.

The intersection method consists of 3 methods: the forward intersection, the backward intersection and the combined intersection. The combined intersection was used to thicken the triangulation network.

Positioning using GNSS technology was used to determine the photogrammetric landmarks. The real-time kinematic method RTK (Real Time Kinematic) radio rover base was used, which allows the transmission of real-time corrections and ensures centimeter accuracy. (Dierwechter et al., 2008; Lwin et al., 2012)

Data acquisition using the principles of aerial photogrammetry is a modern method that allows surveying a large number of data in a short time compared to classical topography methods. The data can be retrieved using opto-electronic or optical-mechanical sensors that are located on board aircraft (airplanes, helicopters, drones). In this case, UAV (unmanned aircraft) technology was used, also called a drone, equipped with an RTK module that allows real-time corrections. (Vorovencii, 2010; Carvajal et al., 2011; Raeva et al., 2016)

Software used to obtain the data:

- Microsoft Excel to perform the necessary calculations;

- Microsoft Word for the elaboration of the documentation;

- Leica Geo Office Tools for data transfer from the total station;

- AutoCAD 2016 for making plans;

- TopoLT, a program that runs inside the AutoCAD program, for making plans;

- DJI Mission Planner for flight planning;

- AgiSoft Metashape for image processing and orthophotoplan;

- Global Mapper 19 used for photogrammetric data processing;

- TransDatRo for transforming the coordinates taken with the drone;

- ProfLT for the realization of topographic profiles.

\section{RESULTS AND DISCUSSIONS}

The ground control points that will be used for the photogrammetric method were materialized in the field and then their position was determined.

The real-time RTK radio rover base measurement method allows the determination of a centimeter accuracy.

The coordinates of the points thus taken shall be within the accuracy of $0,010 \mathrm{~m}$ and $0,034 \mathrm{~m}$ horizontally and 0,013 $m$ and $0,053 \mathrm{~m}$ vertically. 
Aerial photography project: The first step is to carry out the aerial photography project which establishes: Aerial photography direction; Medium level plan; Aerial photography scale; Flight height; Longitudinal and transverse coverage of frames; The distance between the axes of the shooting bands; Total number of frames; Time required for aerial photography.

The DJI Mission Planner program was used to plan each flight, which is the default software of the DJI Phantom 4 RTK drone. There were 8 flights at intervals of about $2 \mathrm{~km}$. The drone has an RTK module that works on GPS frequencies: L1/L2, GLONASS: L1/L1, BeiDou: B1/B2 and Galileo: E1/ E5a and thus ensures a positioning accuracy of $\pm 1.5 \mathrm{~cm}+1 \mathrm{ppm}$ RMS (error square mean) vertically and $\pm 1 \mathrm{~cm}+1 \mathrm{ppm}$ horizontally.

The flight plan established the aerial photography area and the planning method as linear at an average flight altitude of 170 meters, front and side image overlap of over $70 \%$ for the area of interest and thus acquired a number of 1753 images. The camera used for taking images has a 1-inch sensor and a resolution of 20 megapixels.

Through the RTK aerial photography method, the drone was permanently connected to a base, permanent station, from where corrections were transmitted, improving the coordinates of the drone. This was done by activating the RTK function in the default software. After connecting to the permanent station you can see elements such as: latitude, longitude and altitude, but also the number of satellites to which the aircraft is connected. The coordinates were taken from the WGS84 projection system (Global Geodetic System 1984), and they were transcalculated in the TransDat application.

Due to the fact that the RTK method was used, the required number of ground control points was lower, and the accuracy thus obtained is at the centimeter level.

The resulting orthophotoplan has a ground resolution of $4.19 \mathrm{~cm} /$ pixel, and the digital elevation model has a resolution of $16.7 \mathrm{~cm} /$ pixel and a density of 35.7 points per square meter (Figure 1).

Following the data processing, the Agisoft Metashape application generated a processing report that includes details about the location of the camera, residual errors, camera orientation errors, etc. The data processing time was 2 hours and 21 minutes

Figure 2 shows the overlaps of the image overlap displayed with different colors. The areas with blue are covered in more than 9 photos, and the number gradually decreases to the red color in which the area is included in only 1 photo. A number of 1853 images were taken; The flight height was $170 \mathrm{~m}$; The ground resolution is $4.19 \mathrm{~cm} /$ pix; The covered area is $6.65 \mathrm{~km} 2$; Number of aligned frames: 1853 (Camera stations) Connection points: 2,101,904, connection points are the points that can be identified in 2 or more images in the cloud of connection points; Re-projection error: $0.485 \mathrm{~cm} /$ pixel, being the error corresponding to the distance between the projected point and the measured point; Screenings: $6,187,427$.

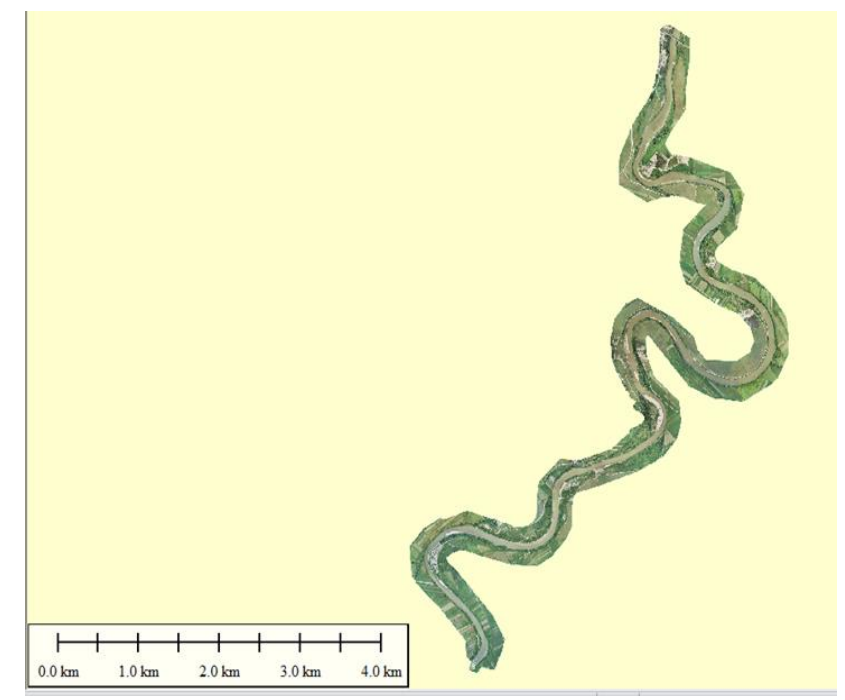

Figure 1. Ortophotomap

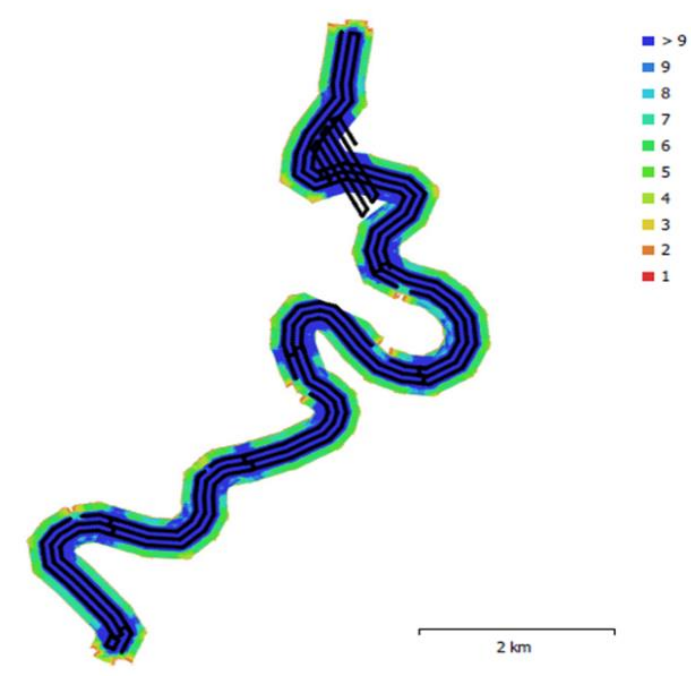

Figure 2. Flight plan and overlapping images taken

The ground control points are distributed according to Figure 3 and are marked with black dots. The errors of the X and Y coordinates of the ground control points are represented by the shape of the ellipse, and the errors of the $\mathrm{Z}$ coordinate are represented by the color of the ellipse. They are between $-8 \mathrm{~cm}$, represented by the color blue and $+8 \mathrm{~cm}$, represented by the color red.

The total number is 18 points, the error on the X coordinates is $1.0477 \mathrm{~cm}$, for $\mathrm{Y} 1.3595 \mathrm{~cm}$ and for Z 2.35124 . The $\mathrm{XY}$ error means the mean square error for the ground control point locations and is $1.712 \mathrm{~cm}$, and the total error involves the average of the locations of all ground control points and is $2.90846 \mathrm{~cm}$. The elevations are gradually represented by the colors, from blue to red, with red being represented the elevations of up to $210 \mathrm{~m}$. The digital elevation model has a 
resolution of $16.7 \mathrm{~cm} /$ pix; Density of points is 35.7 points $/ \mathrm{m}^{2}$ (average number of points in the cloud of dense points per square meter)(Figure 4).

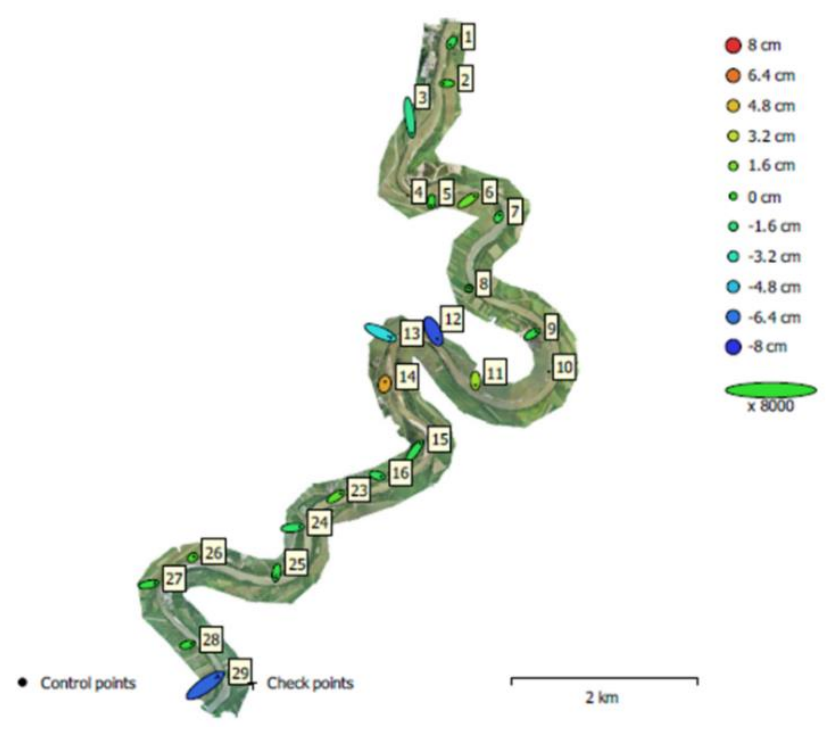

Figure 3. Locations of ground checkpoints and estimated errors

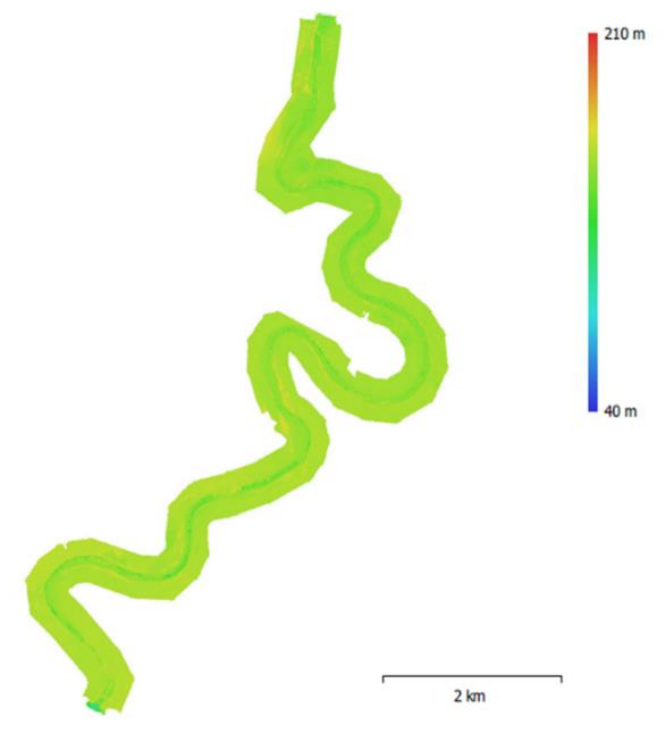

Figure 4. Digital elevation model

For the determination of the minor riverbed, transversal profiles were drawn up from about 200 in 200 meters. Profiles were vectorized in Global Mapper and saved in .dxf format, then uploaded to AutoCAD. Cross-sectional profiles have been created using the ProfLT.

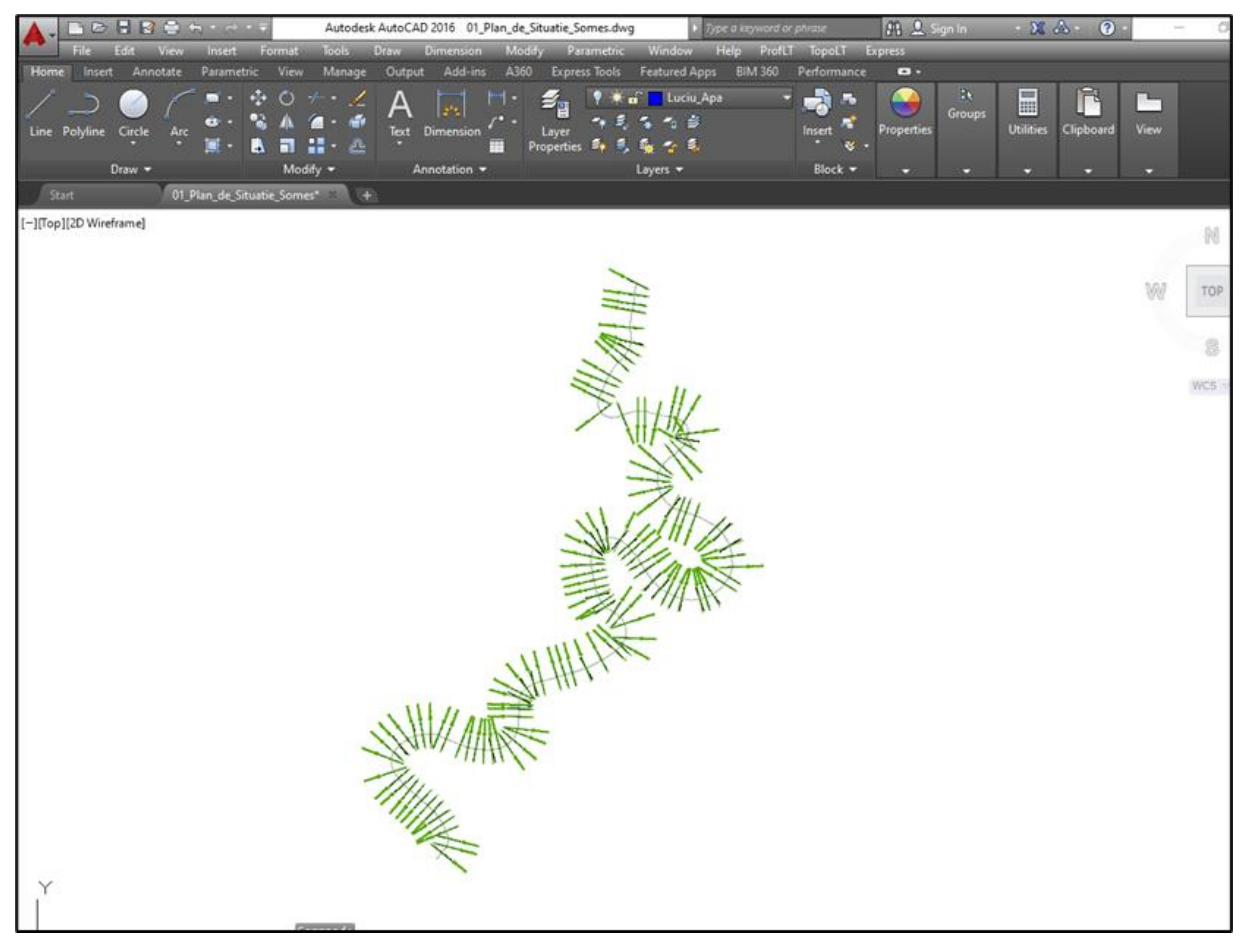

Figure 5. Prof LT Profiles

Figures 6 and 7 show the cross profiles 1, 2 and 3. The scales used are 1:1000 for distances and 1:500 for elevations. It should be mentioned that in the area of water gloss the elevations are informative because the photogrammetric method does not provide precision in determining the ground under water. Elevations outside the water gloss are accurate, being determined based on the digital terrain elevation mode. 


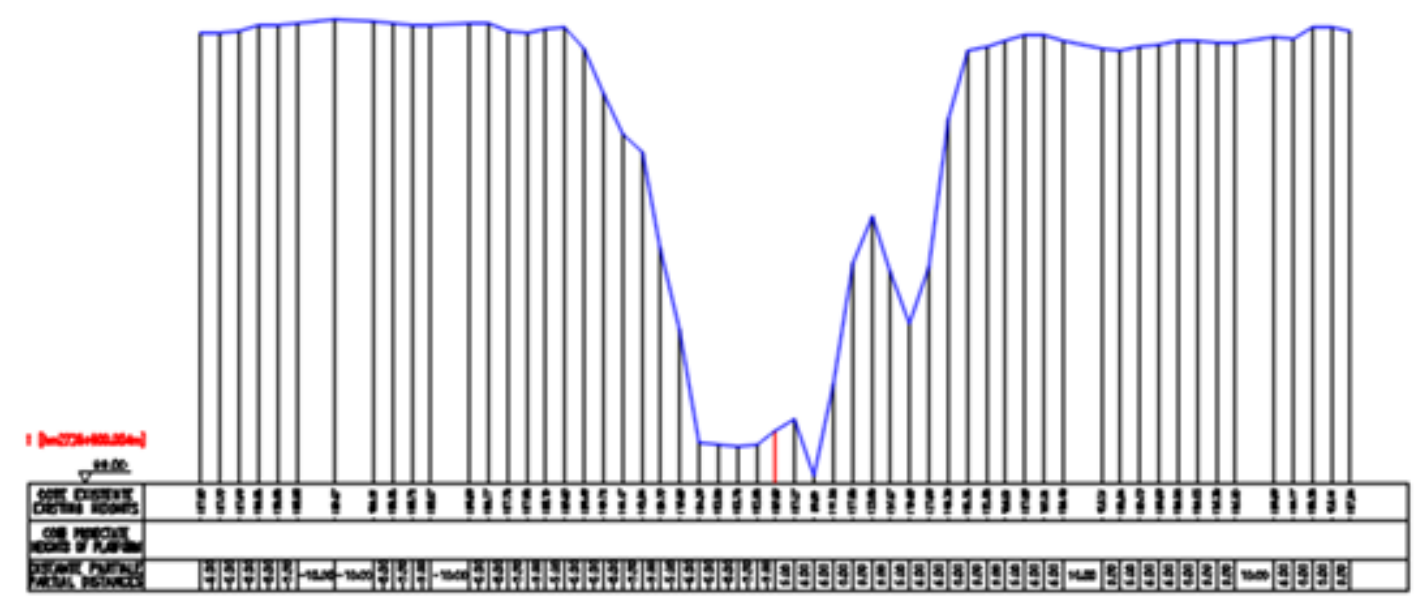

Figure 6. Cross section 1
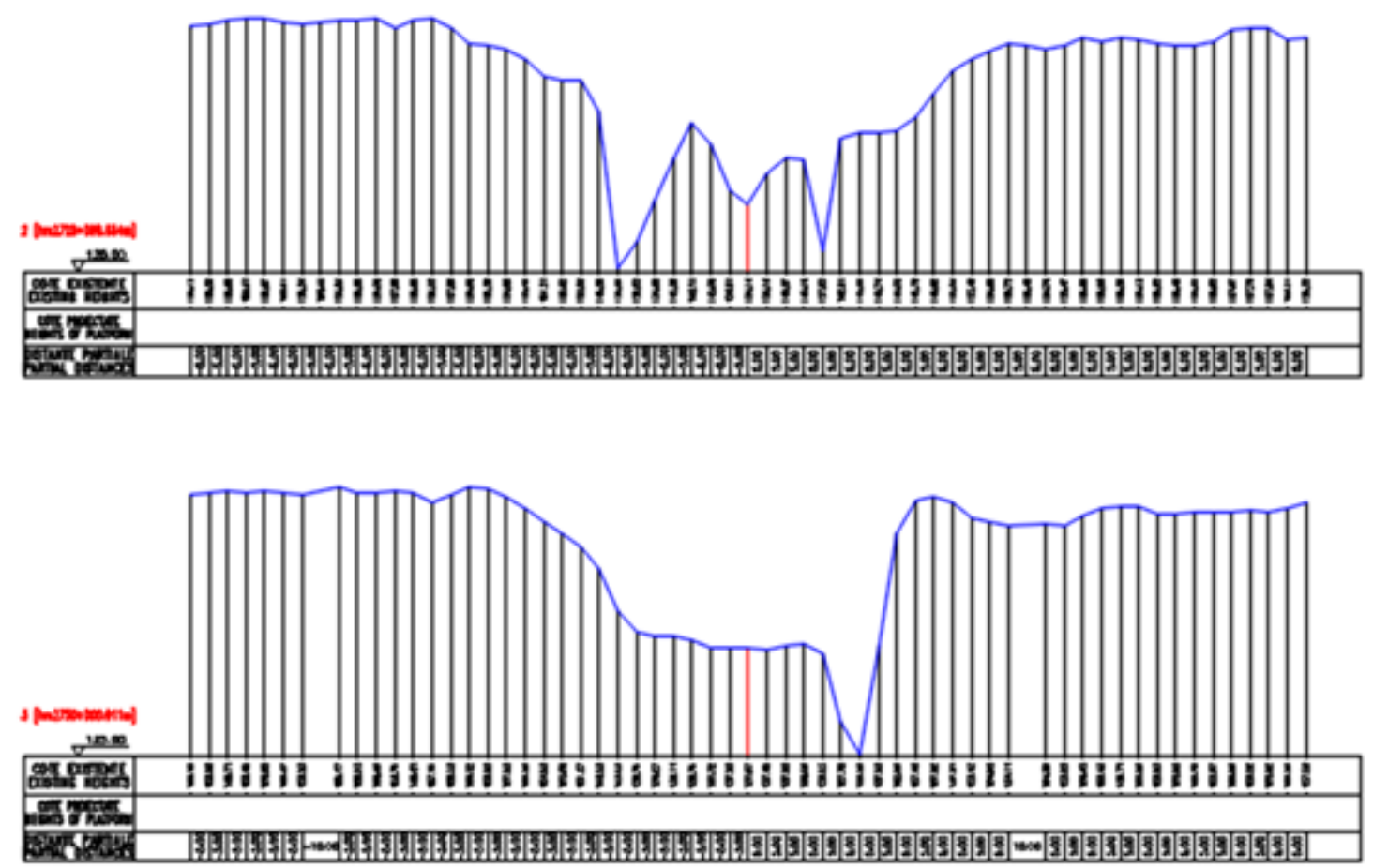

Figure 7. Cross section 2 and 3

For the calculation of the surfaces, the analytical procedure was chosen. The related calculation formulas are the following:

$$
2 S=\sum_{I=1}^{n} x_{i}\left(y_{i+1}-y_{i-1}\right) \quad 2 S=\sum_{I=1}^{n} y_{i}\left(x_{i-1}-x_{i+1}\right)
$$

The areas were calculated using the TopoLT program following the formulas written above, and the results obtained are the following:

For the minor riverbed related to Ardusat ATU: $\mathrm{S}=466294.03 \mathrm{mp}$

For the minor riverbed related to ATU Fărcasa: $\mathrm{S}=1761151.03 \mathrm{mp}$

The total area resulting for both ATUs is: $\mathrm{S}=2227445.06 \mathrm{mp}=222,745$ ha

The first registration documentation was made in accordance with the Order of the general director of the National Agency for Cadastre and Real Estate Advertising no. 700/2014, updated in 2020.

\section{CONCLUSIONS}

Within the present project, the procedure by which the minor riverbed of the Somes River was registered in the Land Book was presented. Measurements were performed using GNSS technology and the UAV photogrammetric method, and several software were used for data processing and drawing. 
The use of modern equipment and state-of-the-art technology in making measurements helps reduce time spent in the field and increase labor productivity.

After analyzing the methods used and the results obtained in this study, it can be concluded that GNSS measurements significantly reduce the data acquisition time, compared to classical measurement methods. Also, the photogrammetric method obtains a complex degree of data, and the use of a drone equipped with RTK mode ensures a higher accuracy of point coordinates and involves the placement of a smaller number of control points on the ground compared to the traditional method of taking drone data.

In large-scale works, which are large and require high precision, I recommend the use of modern equipment and stateof-the-art processing software because they increase work efficiency and can provide a high degree of detail.

Author Contributions: M.E.N., T.S. and I.D.P. Conceived and designed the analysis; M.E.N., J.D., S.C., E.E.Ş. and I.L. Collected the data; P.I.D., I.D.P., F.M. and I.C. Contributed data or analysis tools; M.E.N., T.S., S.C. and E.E.Ş. Performed the analysis; M.E.N. and T.S. Wrote the paper.

Funding Source: The authors received no specific funding for this work.

\section{Acknowledgments}

This research did not receive any specific grant from funding agencies in the public, commercial, or not-for-profit sectors.

\section{Conflicts of Interest}

The authors declare that they do not have any conflict of interest.

\section{REFERENCES}

1. Carvajal F, Aguera F, Perez M (2011). Surveying a Landslide in a Road Embankment Using Unmanned Aerial Vehicle Photogrammetry. ISPRS, XXXVIII-1/C22: 201-206.

2. Dierwechter Y, Carlson T (2008). Effects of urban growth boundaries on residential development in Pierce County, Washington. The Professional Geographer 59(2): 209-220.

3. Lwin KK, Murayama Y, Mizutani C (2012). Quantitative versus Qualitative Geospatial Data in Spatial Modelling and Decision Making. Journal of Geographic Information System (4): 237-241.

4. Neuner J (2000). Global Positioning Systems. Matrix Rom Publishing House, Bucharest.

5. Păunescu C, Dimitriu SG, Mocanu V (2012). A position determination system using the satellite system (GNSS). Bucharest University Publishing House.

6. Peyret F, Betaille D, Hintzy G (2000). High-precision application of GPS in the field of real-time equipment positioning. Automation in Construction, 9: 299-314.

7. Pirti A, Yucel MA, Gumus K (2013). Testing Real Time Kinematic GNSS (GPS and GPS/GLONASS) methods in obstructed and unobstructed sites. Geodetski Vestnik 57(3): 498-512.

8. Raeva PL, Filipova SL, Filipov DG (2016). Volume computation of a stockpile - a study case comparing GPS and UAV measurements in an open pit quarry. The International Archives of the Photogrammetry, Remote Sensing and Spatial Information Sciences, XXIII ISPRS Congress, Prague, Czech Republic, XLI-B1: 999-1004.

9. Sălăgean T, Șuba EE, Pop ID, Matei F, Deak J (2019). Determining Stockpile Volumes Using Photogrammetric Methods. Scientific Papers. Series E. Land Reclamation, Earth Observation \& Surveying, Environmental Engineering. Vol. VIII: 114-119.

10. Sălăgean T, Șuba EE, Moscovici AM, Păunescu V, Călin M, Iliescu A, Pop ID (2019). The Use of UAV in Urban Public Utility Systems. Modern Technologies for the 3rd Millenium, April 4-5, 2019, Oradea, Romania, ISBN 978-88-8772941-2: 67-72.

11. Șuba EE, Sălăgean T, Onose D, Rusu T, Chiorean S, Matei F, Pop I (2017). Creating a Mathematical Flood Area Model for Nistru River, Maramureș County. AgroLife Scientific Journal, Volume 6, Number 1: 249-256.

12. Treitz P (2004). Remote sensing for mapping and monitoring land-cover and land-use change. Progress in Planning 61:269-279.

13. Vorovencii I (2010). Photogrammetry. Matrixrom Publishing House, Bucharest, Romania, ISBN 978-973-755-580-9. 